\title{
An investigation on surface roughness of granite machined by abrasive waterjet
}

\author{
GOKHAN AYDIN*, IZZET KARAKURT and KERIM AYDINER \\ Department of Mining Engineering, Karadeniz Technical University, 61080 Trabzon, Turkey
}

MS received 8 April 2010; revised 18 June 2010

\begin{abstract}
Abrasive waterjet (AWJ) cutting is an emerging technology which enables the shaping of practically all engineering materials. However, AWJ cutting may cause roughness and waviness on the cut surface. This significantly affects the dimensional accuracy of the machined part and the quality of surface finish. In this study, the surface roughness of three granites is experimentally investigated for varying process parameters in abrasive waterjet. The philosophy of the Taguchi design is followed in the experimental study. Effects of the control (process) factors on the surface roughness are presented in terms of the mean of means responses. Additionally, the data obtained are evaluated statistically using the analysis of variance (ANOVA) to determine significant process parameters affecting the surface roughness. Furthermore, effects of the material properties on the surface roughness are assessed. It was statistically found that the water pressure and the abrasive flow rate are the most significant factors influencing the surface roughness of granites. Additionally, a consistent relationship between the material grain size and surface roughness of the granites was observed.
\end{abstract}

Keywords. Abrasive waterjet; granite; grain size; surface roughness.

\section{Introduction}

The use of natural stones has dramatically increased in the last years all over the world. The stone products, in particular granite, are more and more used for outside and inside flooring/covering, home and urban furnishing, civil building and sacred art (Carrino et al 2001). With this growing commercial market and competition, there is an increasing demand for the innovative manufacturing processes for natural stones including marble, travertine and granite.

Due to their composition, the machining and processing of natural stones (especially granite) with the traditional systems have some difficulties. Therefore, new cutting methods which are able to increase the machining efficiency by minimizing the production time and the costs are required.

Among the innovative manufacturing processes, abrasive waterjet (AWJ) cutting has found a broad application area as an alternative technology to traditional systems in processing and machining of natural stones as well as almost all engineering materials. It has various distinct advantages over traditional cutting technologies, such as having no thermal distortion, high machining versatility, high flexibility, small cutting forces and special geomet-

\footnotetext{
*Author for correspondence (gaydin@ktu.edu.tr)
}

ric cuttings (Aydin et al 2010). A typical waterjet system is schematically illustrated in figure 1 . The intensity and the efficiency of the machining process depend on several AWJ process parameters. These include hydraulic, abrasive, work material and cutting parameters (Hashish 1991; Valicek et al 2007).

AWJ has the potential of becoming one of the principal material removal technologies; however, several shortcomings substantially inhibit the use of this technology. Among the shortcomings inhibiting the usability of abrasive waterjet, cut depth, surface roughness and waviness (striation) of generated surfaces are of the principal deficiencies of AWJ.

The surface structure and kerf geometry of a cut by abrasive waterjets results from the physics of the cutting

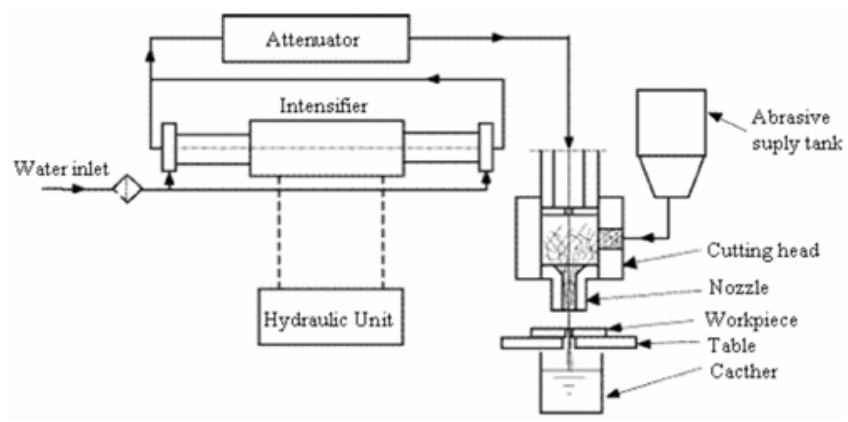

Figure 1. A schematic illustration of an abrasive type waterjet cutting system. 
process. In the existing literature, many authors have attempted to analyze and describe the surface structure. Hashish (1993) visualized the AWJ cutting process using a high-speed photography of the material removal process in a plexiglass sample. Surface irregularities in particular in the form of striations were studied by Lemma et al (2002) and Hloch et al (2007). Momber et al (1993) investigated the abrasive grain size distribution on the abrasive waterjet machining process. It was suggested that striations were the inherent characteristic feature to the AWJ cutting process. More recently, surface roughness of three granites were experimentally investigated for various process parameters by Karakurt et al (2010). Surface topography based on the waviness and roughness was characterized by Guo et al (1993). Chao et al (1992) discussed the correlation between the vibration of the nozzle and waviness of the surface profiles. Although the literature is abundant with the relevant investigations, there is a scarcity of research devoted to the cut surface quality of rock. A little number of studies has focused on the investigation of rock cutting performances of AWJ. Amongst them, Cheung and Hurlburt (1976) compared a submerged waterjet with a free jet operating in air for red granite cutting in terms of cut depth. Matsuki et al (1988) expanded the comparison considering the influence of the impinging angle and standoff distance on the cut depth in rock. Further, parameters such as rock temperature, physical properties of rock and process parameters were analyzed to define their influences on the cut depth in rock. Miranda and Kim (1996) analyzed the fractured surfaces of the Rosa de Borba marble and Moca Creme calcareous stone machined by abrasive waterjet.

In this study, the surface roughness of three granites is experimentally investigated for varying process parameters in abrasive waterjet. Furthermore, effects of the material properties on the surface roughness are assessed.

\section{Experimental}

\subsection{Materials and methods}

In the experiments, pre-dimensioned granite specimens of $30 \mathrm{~mm}$ thickness, $200 \mathrm{~mm}$ length and $100 \mathrm{~mm}$ width were cut by a KMT international waterjet cutter driven a 'Model SL-V $50 \mathrm{HP}$ ' intensifier pumping system with operating pressure of up to $380 \mathrm{MPa}$. The main characteristics of the abrasive waterjet cutter are given in table 1 . The motion of the nozzle is controlled by a computer as shown in figure 2 . The main properties of the specimens are given in table 2. Abrasive type used in the study is garnet which consists of chemically $36 \% \mathrm{FeO}, 33 \% \mathrm{SiO}_{2}$, $20 \% \mathrm{Al}_{2} \mathrm{O}_{3}, 4 \% \mathrm{MgO}, 3 \% \mathrm{TiO}_{2}, 2 \% \mathrm{CaO}$ and $2 \% \mathrm{MnO}_{2}$.

Surface roughness is a measure of the technological quality of a product and a factor that greatly influences manufacturing cost. It describes the geometry and surface textures of the machined parts (Nalbant et al 2007; Çaydaş and Hasçalık, 2008). There are several ways to describe surface roughness, such as the roughness average $\left(R_{\mathrm{a}}\right)$, the root-mean-square (rms) roughness $\left(R_{\mathrm{q}}\right)$ and the maximum peak-to-valley roughness $\left(R_{\max }\right)$, etc. $R_{\mathrm{a}}$ is defined as the arithmetic value of the profile from centreline along the sampling length (Özçelik et al 2005).

Surface roughness measurements of the cut surfaces of the granite specimens were made using a stylus-type profilometer, Mitutoyo Surftest SJ-301 whose principals are schematically described in figure 3 . Due to the variability of surface finish data, eight measurements for each specimen on each cut were made at the upper zone (smooth zone) of the cut surface and the average was taken as the final reading for the surface roughness $\left(R_{\mathrm{a}}\right)$.

\subsection{Design of experiments}

Design of experiments (DOE) is the process of planning the experiments considering the process parameters at different levels. Experimental design using Taguchi's method provides a simple, efficient and systematic approach for an optimal design of experiments to assess the performance, quality and cost (Davim 2003). Statistically designed experiments are conducted more efficiently as they consider multiple factors simultaneously and they can detect important interactions with minimum number of experiments unlike traditional experimentation which considers only one factor at a time while keeping the other parameters constant. For example, one need to conduct $3^{5}$ (243) experiments when five factors, each varied

Table 1. Main properties of the abrasive waterjet cutter.

\begin{tabular}{ll}
\hline Machine model & SL-V 50 HP (KMT) \\
Energy consumption (kwh) & 40 \\
Abrasive consumption (g/min) & $100-400$ \\
Nozzle diameter (mm) & $1 \cdot 1$ \\
Nozzle length $(\mathrm{mm})$ & 75 \\
Water consumption $(1 / \mathrm{m})$ & $3 \cdot 8$ \\
\hline
\end{tabular}

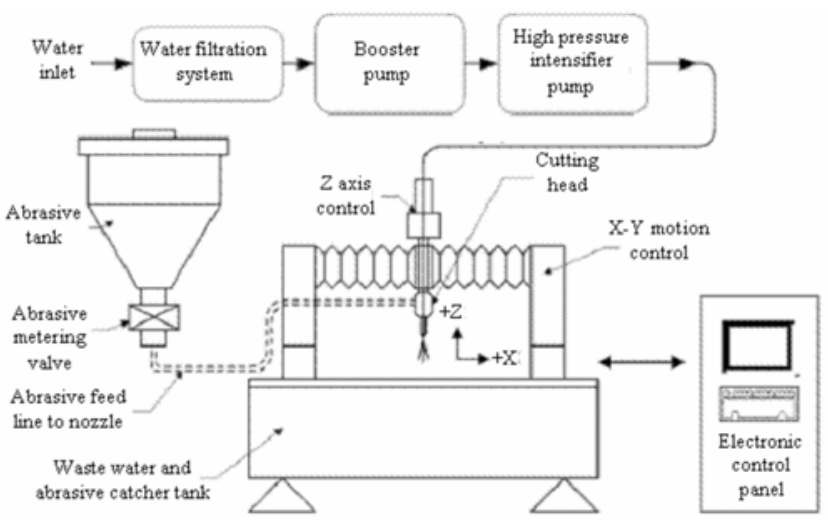

Figure 2. A schematic illustration of the experimental set-up. 
Table 2. Main properties and mineralogical compositions of the specimens.

\begin{tabular}{llrrr}
\hline \multicolumn{1}{c}{ Features } & $\begin{array}{r}\text { Rosa } \\
\text { Giresun }\end{array}$ & $\begin{array}{r}\text { Vizon } \\
\text { Minho }\end{array}$ & $\begin{array}{c}\text { Balaban } \\
\text { Green }\end{array}$ \\
\hline Physical and mechanical & Mean grain size $(\mathrm{mm})$ & 13.16 & 7.97 & 2.88 \\
& Water absorption $(\%)$ & 0.30 & 0.20 & 0.30 \\
& Specific bulk density $\left(\mathrm{KN} / \mathrm{m}^{3}\right)$ & 27.2 & 26.7 & 26.6 \\
& Uniaxial compressive strength $(\mathrm{MPa})$ & 110 & 135 & 94.5 \\
& Flexural strength $(\mathrm{MPa})$ & 15.3 & 18.5 & 15.2 \\
& Ultrasonic Velocity $(\mathrm{m} / \mathrm{s})$ & 4865 & 5555 & 5067 \\
Mineralogical composition $(\%)$ & 54 & 52 & 52 \\
& Alkali feldspar & 29 & 14 & 23 \\
& Quartz & 10 & 24 & 13 \\
& Plagioclase & 5 & 4 & 8 \\
& Biotite & 2 & 3 & 4 \\
\hline
\end{tabular}

Table 3. Process parameters and their levels considered for the experimentation.

\begin{tabular}{lllrrrr}
\hline Symbol & Machining parameters & Units & Level 1 & Level 2 & Level 3 & Level 4 \\
\hline $\mathrm{T}$ & Traverse speed & $\mathrm{mm} / \mathrm{min}$ & 100 & 150 & 200 & 250 \\
$\mathrm{M}$ & Abrasive flow rate & $\mathrm{g} / \mathrm{min}$ & 150 & 200 & 250 & 300 \\
$\mathrm{D}$ & Standoff distance & $\mathrm{mm}$ & 2 & 4 & 6 & 8 \\
$\mathrm{P}$ & Water pressure & $\mathrm{MPa}$ & 200 & 250 & 300 & 350 \\
$\mathrm{~S}$ & Abrasive size & $\mathrm{mesh}$ & 80 & 120 & & \\
\hline
\end{tabular}

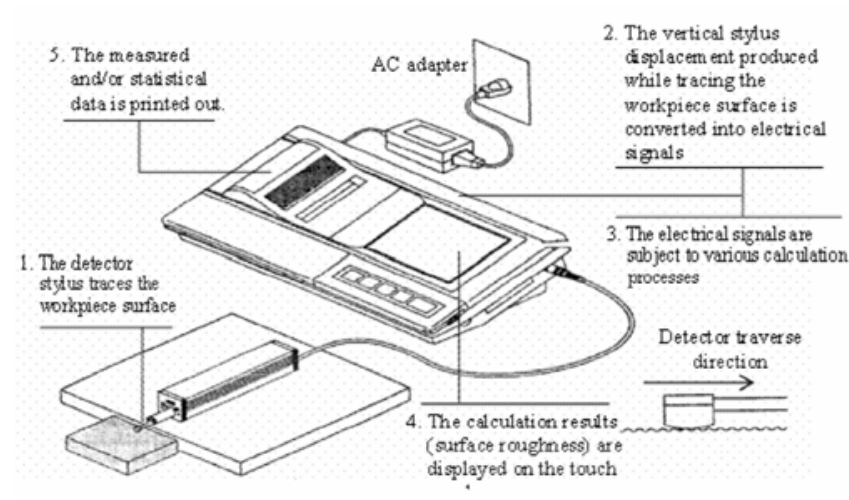

Figure 3. A schematic description of Mitutoyo Surftest SJ-301.

at three levels are considered. In the present work, four factors varied at four levels and one factor varied at two levels are considered. The range of different process parameters and factor levels used for this study are shown in table 3 . Based on Taguchi's method DOE with five factors a $\mathrm{L}_{16}\left(4^{4} \times 2^{1}\right)$ orthogonal arrays table with 16 rows (corresponding to the number of experiments) was selected for the experimentation (table 4). A statistical ANOVA test was also performed to decide process factors significantly affecting the surface quality.

\section{Results and discussion}

\subsection{Analysis of variance (ANOVA)}

In the analysis of variance (ANOVA), $F$-ratio was used to determine significant process factors. $F$-ratio is a tool to see which process factor has a significant effect on the surface roughness of the granite specimens. An $F$-ratio is calculated from the experimental results and then compared to the critical value. If the $F$-ratio calculated is larger than the $F$ critical value, it is an indication that the statistical test is significant at the confidence level selected. If not, it indicates that the statistical test is not significant at the confidence level. In addition, larger $F$-ratio value indicates that there is considerable effect on the performance characteristic due to the variation of the process parameters (Azmir et al 2007; Azmir and Ahsan, 2008).

This analysis was carried out for the confidence level of $95 \%$. Table 5 shows the result of ANOVA for machining outputs. It was found that among the factors $P$ (water pressure) is the most significant factor influencing the assessment of the surface roughness of the Rosa Minho and the Giresun Vizon in table 5, followed by control factors $D$ (standoff distance) for the Rosa Minho and $T$ (traverse speed) for the Giresun Vizon. It was also found that the control factors $M$ (abrasive flow rate), $D$ (standoff distance) and $S$ (abrasive size) failed the test of significance at $95 \%$ confidence level and are considered insignificant for the Giresun Vizon, while the control factors $S$ (abrasive size) was only found to be insignificant for the Rosa Minho. The control factors $M$ (abrasive flow rate), $D$ (standoff distance) and $P$ (water pressure) were found to be significant for the surface roughness of the Balaban Green, respectively. Additionally, the control factors $T$ (traverse speed) and $S$ (abrasive size) were found insignificant for the Balaban Green. 
Table 4. Experimental layout for $\mathrm{L}_{16}\left(4^{4} \times 2^{1}\right)$ orthogonal array.

\begin{tabular}{llllll}
\hline & \multicolumn{5}{c}{ Factors } \\
\cline { 2 - 6 } Experiment number & $\mathrm{T}$ & $\mathrm{M}$ & $\mathrm{D}$ & $\mathrm{P}$ & $\mathrm{S}$ \\
\hline 1 & 1 & 1 & 1 & 1 & 1 \\
2 & 1 & 2 & 2 & 2 & 1 \\
3 & 1 & 3 & 3 & 3 & 2 \\
4 & 1 & 4 & 4 & 4 & 2 \\
5 & 2 & 1 & 2 & 3 & 2 \\
6 & 2 & 2 & 1 & 4 & 2 \\
7 & 2 & 3 & 4 & 1 & 1 \\
8 & 2 & 4 & 3 & 2 & 1 \\
9 & 3 & 1 & 3 & 4 & 1 \\
10 & 3 & 2 & 4 & 3 & 1 \\
11 & 3 & 3 & 1 & 2 & 2 \\
12 & 3 & 4 & 2 & 1 & 2 \\
13 & 4 & 1 & 4 & 2 & 2 \\
14 & 4 & 2 & 3 & 1 & 2 \\
15 & 4 & 3 & 2 & 4 & 1 \\
16 & 4 & 4 & 1 & 3 & 1 \\
\hline
\end{tabular}

The last column of table 5 indicates the percentage of each factor contribution $(P)$ on the total variation, thus exhibiting the degree of influence on the result (Şahin 2009). It is important to observe the $P$-values in the table.

From the analysis of ANOVA, the factor $P(48 \cdot 40 \%)$ showed a high significant effect. It was followed by stand-off distance $(33.04 \%)$, and the abrasive flow rate (13.11\%) for the Rosa Minho. While the factors $M$ $(50 \cdot 50 \%)$ showed a high significant effect, followed by $D$ $(19.47 \%)$ and $P(18.30 \%)$ for the Balaban Green, the water pressure $(43.54 \%)$, the traverse speed $(26.23 \%)$ and the stand-off distance $(22 \cdot 46 \%)$ showed high significance, respectively for the surface roughness of the Giresun Vizon.

\subsection{Effect of the control factors on the surface roughness}

In AWJ process, as the waterjet moves faster, less number of particles is available which pass through a unit area. Thus, less number of impacts and cutting edges will be available per unit area that results in rougher surfaces. Consequently, the surface roughness is higher at higher levels of the traverse speed for all the rocks tested as shown in figure 4(a). The highest surface roughness is occurred for the granite that has the medium-grained as followed from table 1, whereas the lowest is for the granite which is fine-grained.

In case of the abrasive flow rate, the higher the abrasive flow rate, the higher the number of particles involved in the mixing and cutting processes. An increase in abrasive flow rate means a proportional increase in the cut depth. When the abrasive flow rate is increased, the cut surface becomes smoother and low surface rough- nesses are expected due to the more number of impacts and cutting edges available per unit area. However, the roughness of the granites increases with an increase in abrasive flow rate (figure 4(b)). One possible reason for this phenomenon, as stated by Azmir and Ahsan (2009), is the inter-collision of particles among themselves which in turn a loss of kinetic energy.

In case of the stand-off distance, higher stand-off distance results in higher surface roughness in all granites (figure 4(c)). Basically, higher stand-off distances are related to the effective jet diameter. That is, when the jet spreads out of the nozzle, it diverges and the effective jet diameter is reduced. This may also cause an increase of vulnerability to the external drag from surrounding environment. As a consequence, increased jet diameter or diverged jet can lose easily its kinetic energy and may produce rougher surfaces. Earlier analysis have revealed that the higher stand-off distances result in a constant increase in the surface roughness (Chen et al 1996; Wang and Wong 1999; Karakurt 2007).

In case of the water pressure, higher water pressure increases the kinetic energy of the individual particles inside the jet and enhances their capability for the material removal. However, higher water pressure may also result in random particle collisions between particles due to the acceleration and also due to more energy disbursement from the abrasives to the area bombarded by the waterjet, more rougher cut surfaces can be obtained. As depicted in figure 4(d), the surface roughnesses of all rocks increase with an increase in water pressure.

In case of the abrasive size, an abrasive with smaller mesh number has a larger average value of particle size and fewer particles per unit weight. Also, Zeng and Kim (1996) stated that larger particles cut the materials faster owing to the higher particle inertia; however, the surface finish is rougher in the cutting wear zone although the zone itself is substantially extended. Figure 4(e) illustrates that the lower surface roughness is obtained by an abrasive with larger mesh number for the Rosa Minho, while the higher roughnesses are achieved by an abrasive with smaller mesh number.

Based on the basic results of the study, a consistent relationship between the material properties such as mineral content and surface roughness could not be found. However, it can be concluded that a relation between surface roughness and mean grain size of the granites was observed. The regression model is also an evidence of this powerful relation (figure 4(f)).

In this study, the roughness measurements were performed along a line of $100 \mathrm{~mm}$. Therefore, the friction coefficient values include the measurement results from both grain insides and grain boundaries. As is well known, the coarse-grained granite has relatively large grains as compared to the medium- and fine-grained granites. In coarse-grained granite, there is relatively lower amount of grain boundaries in a specific area, and thus there is a 

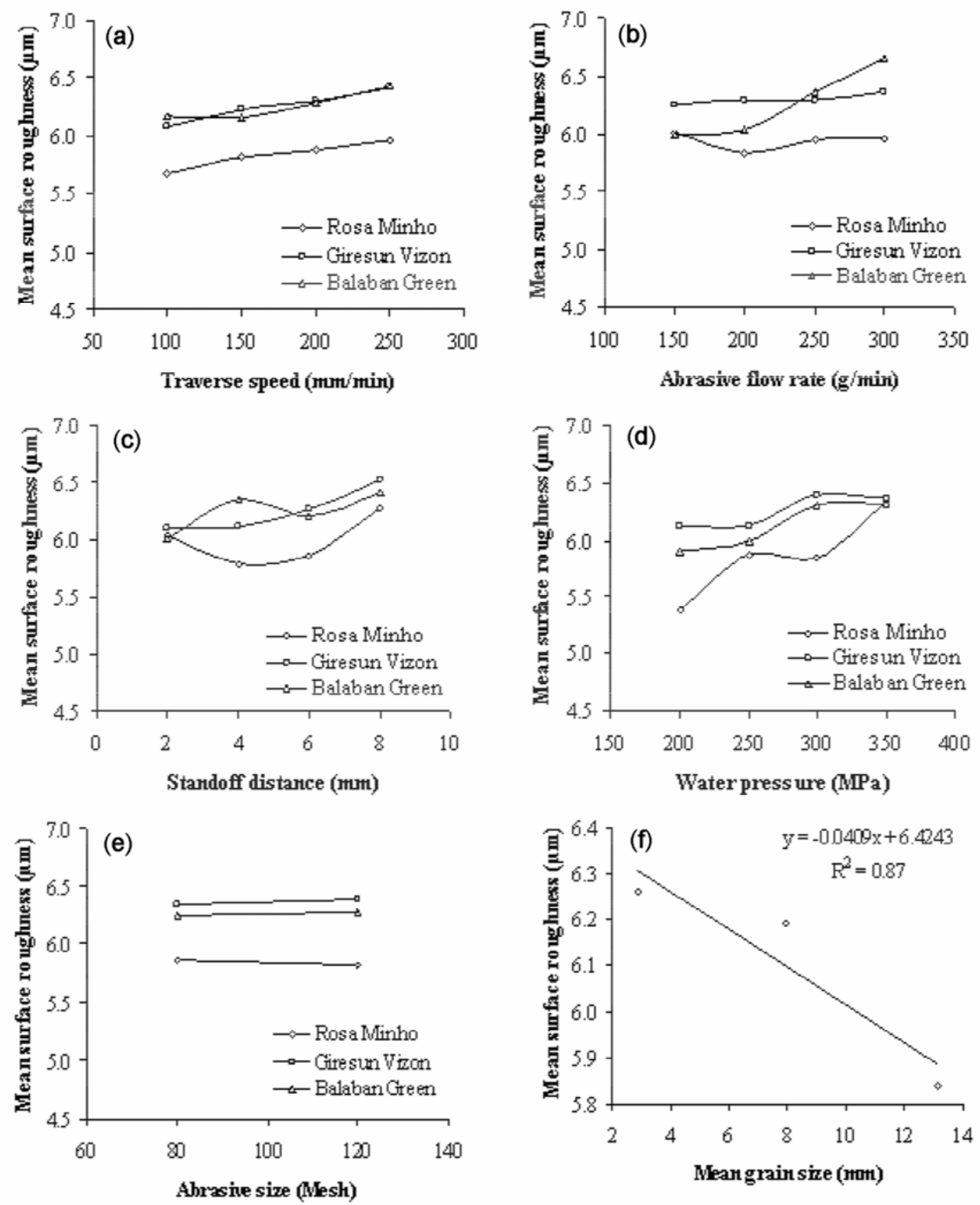

Figure 4. Effect of the control factors on the surface roughness of the granite: (a) the traverse speed, (b) the abrasive flow rate, (c) the stand-off distance, (d) the water pressure, (e) the abrasive size, (f) the grain size on the surface roughness.

minor effect on the friction coming from the grain boundaries that have relatively higher roughness as shown in figure 5. Whereas, fine-grained structures have much more grains that have higher amount of grain boundaries along a specific line. Therefore, during measuring the friction coefficient, the possibility of intersecting the grain boundaries which have higher roughness compared to the grain interior are higher than the coarse-grained granites.
This results in intersecting higher number of grain boundaries leading to high friction coefficient.

For showing the cutting surface morphology, some micrographs were taken in using scanning electron microscope (SEM) as shown in figure 6. From these SEM micrographs, all granites have almost the same cutting surface morphologies. In general, one can see the smooth surfaces with some fractured areas because of the 
Table 5. Results of analysis of variance (ANOVA) for the surface roughnesses of the granites.

\begin{tabular}{|c|c|c|c|c|c|c|}
\hline Sample & Source & Degree of freedom & Sum of squares & Mean square & $F$-ratio & Contribution (\%) \\
\hline Rosa Minho & $\begin{array}{l}\mathrm{T} \\
\mathrm{M} \\
\mathrm{D} \\
\mathrm{P} \\
\mathrm{S} \\
\text { Error } \\
\text { Total }\end{array}$ & $\begin{array}{r}3 \\
3 \\
3 \\
3 \\
1 \\
2 \\
15\end{array}$ & $\begin{array}{l}0 \cdot 188 \\
0 \cdot 508 \\
1 \cdot 281 \\
1 \cdot 877 \\
0 \cdot 006 \\
0 \cdot 015 \\
3 \cdot 878\end{array}$ & $\begin{array}{l}0.062 \\
0.169 \\
0.427 \\
0.625 \\
0.006 \\
0.007\end{array}$ & $\begin{array}{r}8.14 \\
21.92 \\
55 \cdot 27 \\
80.93 \\
0.88\end{array}$ & $\begin{array}{r}4 \cdot 87 \\
13 \cdot 11 \\
33 \cdot 04 \\
48 \cdot 40 \\
0 \cdot 18 \\
0 \cdot 40 \\
100\end{array}$ \\
\hline Giresun Vizon & $\begin{array}{l}\mathrm{T} \\
\mathrm{M} \\
\mathrm{D} \\
\mathrm{P} \\
\mathrm{S} \\
\text { Error } \\
\text { Total }\end{array}$ & $\begin{array}{r}3 \\
3 \\
3 \\
3 \\
1 \\
2 \\
15\end{array}$ & $\begin{array}{l}0.774 \\
0.065 \\
0.663 \\
1.285 \\
0.041 \\
0 \cdot 122 \\
2.952\end{array}$ & $\begin{array}{l}0.258 \\
0.021 \\
0.221 \\
0.428 \\
0.041 \\
0.061\end{array}$ & $\begin{array}{l}4 \cdot 21 \\
0 \cdot 36 \\
0 \cdot 36 \\
6 \cdot 99 \\
0 \cdot 67\end{array}$ & $\begin{array}{r}26 \cdot 23 \\
2 \cdot 23 \\
22 \cdot 46 \\
43 \cdot 54 \\
1 \cdot 39 \\
4 \cdot 15 \\
100\end{array}$ \\
\hline Balaban Green & $\begin{array}{l}\mathrm{T} \\
\mathrm{M} \\
\mathrm{D} \\
\mathrm{P} \\
\mathrm{S} \\
\text { Error } \\
\text { Total }\end{array}$ & $\begin{array}{r}3 \\
3 \\
3 \\
3 \\
1 \\
2 \\
15\end{array}$ & $\begin{array}{l}0 \cdot 206 \\
1 \cdot 167 \\
0 \cdot 450 \\
0 \cdot 423 \\
0 \cdot 0016 \\
0 \cdot 063 \\
2 \cdot 311\end{array}$ & $\begin{array}{l}0 \cdot 068 \\
0 \cdot 389 \\
0 \cdot 150 \\
0 \cdot 141 \\
0 \cdot 001 \\
0 \cdot 031\end{array}$ & $\begin{array}{r}2.18 \\
12.33 \\
4.75 \\
4.47 \\
0.05\end{array}$ & $\begin{array}{r}8.93 \\
50.50 \\
19.47 \\
18.30 \\
0.07 \\
2.73 \\
100\end{array}$ \\
\hline
\end{tabular}

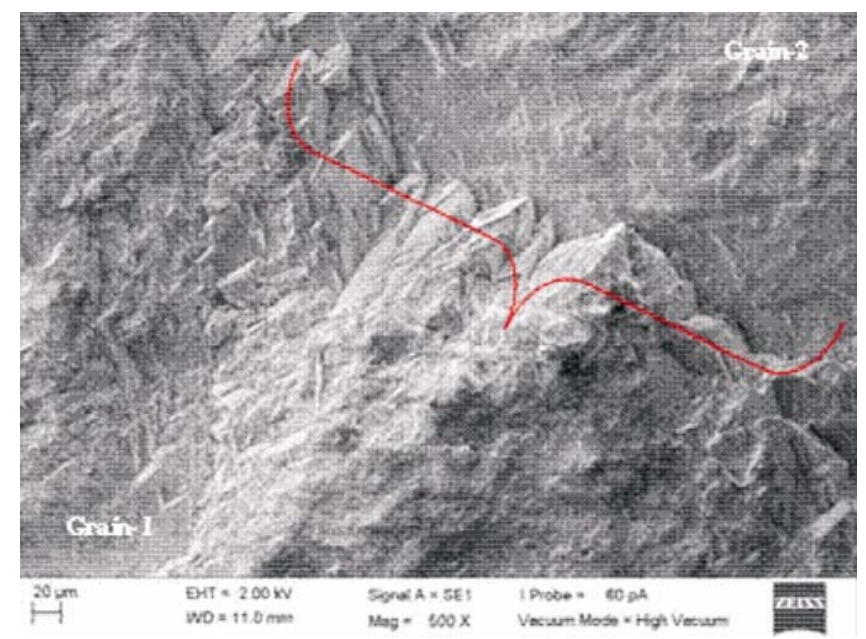

Figure 5. Surface morphology including grains and boundary.

removing of small particles from the matrix during cutting (figure 6). These surfaces have also smeared effect due to the characteristic feature of cutting style as shown on the micrographs.

Additionally, the friction coefficient values or surface roughnesses in coarse- and medium-grained granites are almost the same at some levels of the process parameters. A possible reason for this phenomenon may be explained by the allocation of grains through measurement line. The grains horizontally lying through measurement line will have fewer boundaries than the grains vertically allocated. Therefore, the allocation of the grains through the measurement line may result in obtaining the same values for the coarse- and medium-grained granites. This causes an overlapping, at some levels, of the process parameters.

\section{Conclusions}

This work is a part of ongoing research project and the preliminary results are presented in this article. Based on the results of the work, following conclusions could be made:

(I) In general, higher levels of the process parameters excluding the abrasive size resulted in higher surface roughness in all the granites. On the other hand, small abrasive particles produced lower surface roughnesses in all the granites. 

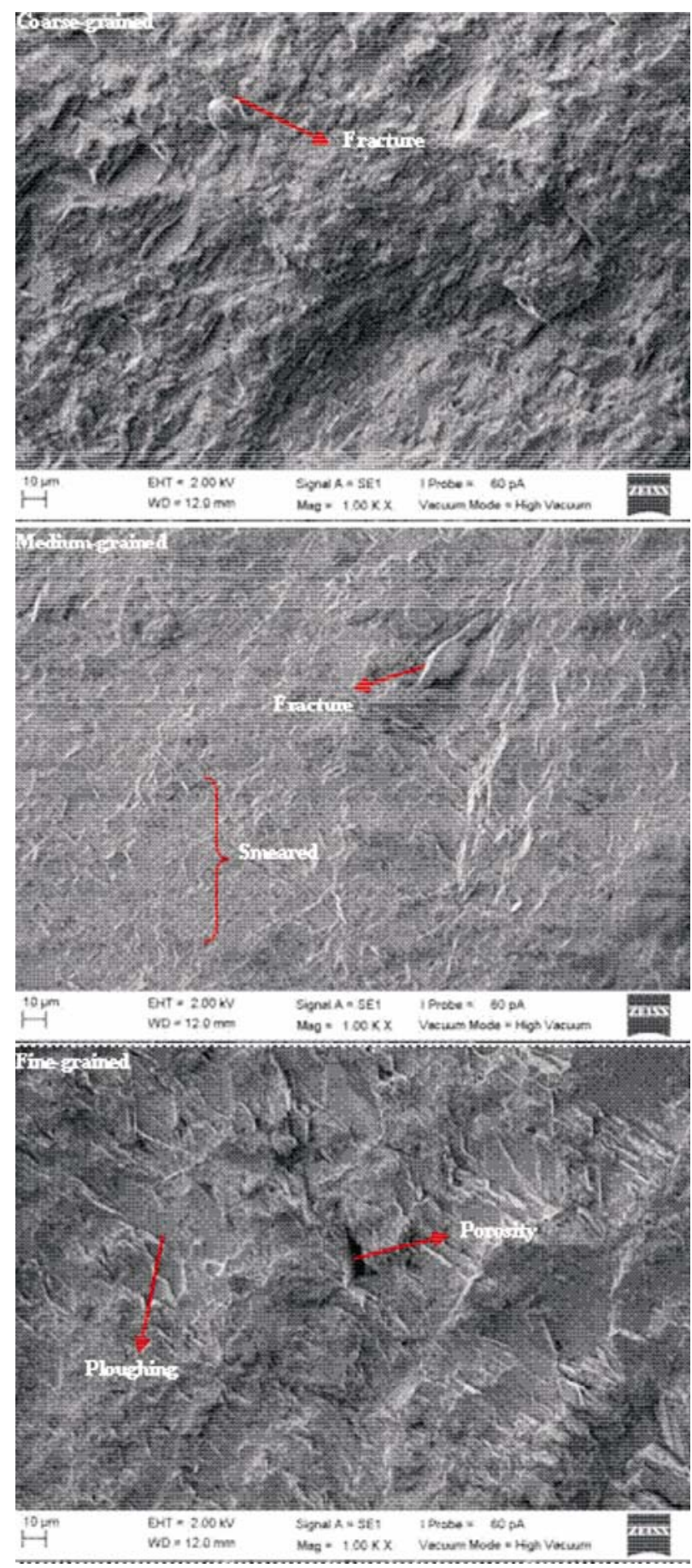

Figure 6. The cutting surface morphology of three granites.

(II) The water pressure and the abrasive flow rate were statistically found to be the most significant factor influencing the surface roughness of the granites, followed by the traverse speed and the stand-off distance with respect to the granite.

(III) When jointly considering the granites, higher surface roughnesses were obtained in the fine-grained granites, followed by the medium- and coarse-grained granite.
(IV) It can be concluded that the grain size of the granites and boundaries between grains play an important role in abrasive waterjet cutting for surface roughness.

\section{Acknowledgements}

The authors would like to express their sincere thanks and appreciation for the financial support to TÜBİTAK (The Scientific and Technological Research Council of Turkey) (Project No 108M370). Moreover, they are thankful to the referee or referees and Assoc. Prof. Dr Gençağa PÜRÇEK for their comments and suggestions to improve the manuscript quality.

\section{References}

Aydin G, Karakurt I and Aydiner K 2010 J. Chambers of Mining Eng. Turkey 4917

Azmir A M and Ahsan K A 2009 J. Mater. Process. Technol. 209, 6168

Azmir M A and Ahsan A K 2008 J. Mater. Process. Technol. 198122

Azmir M A, Ahsan A K and Rahmah A 2007 Proceedings of the International Conference on Mechanical Engineering. Dhaka, Bangladesh, pp 1-6

Carrino L, Polini W, Turchetta S and Monno M 2001 Proceedings of the 11th American Waterjet Conference, Minneapolis-Minnesota, pp 309-327

Çaydaş U and Hasçalık A 2008 J. Mater. Process. Technol. 202 574

Chao J, Geskin E S and Chung Y 1992 Proceedings of the 11th. International Symposium on Jet Cutting Technology, Dordrecht, Netherlands, pp 593-603

Chen L, Siores E and Wong W C K 1996 Int. J. Mach. Tools \& Manufact. 361201

Cheung J B and Hurlburt GH 1976 Proceedings of the 3rd. International Symposium on Jet Cutting Technology (Bedford, England) pp 49-62

Davim J P 2003 J. Mater. Process. Technol. 132340

Guo N S, Louis H and Meier G 1993 Proceedings of the 7th American Water Jet Conference (Seattle, Washington) pp 1-25 Hashish M 1991 Trans. ASME, J. Eng. Ind. 11329

Hashish M 1993 Proceedings of the 7th. American Waterjet Conference (Seattle, WA), pp 205-216

Hloch S, Gomba M, Fabian S and Straka L 2007 Inter. Manufact. Sci. \& Technol. 11

Karakurt İ 2007 M Sc thesis. Karadeniz Technical University, Trabzon, Turkey (in Turkish)

Karakurt I, Aydin G and Aydiner K 2010 J. Earth Sci. Appl. \& Res. (Centre of Hacettepe University) 31 (in press) (in Turkish)

Lemma E, Chen L, Siores E and Wang J 2002 Inter. J. Mach. Tools \& Manufact. 42781

Matsuki A, Okumura K and Nakadate H 1988 Proceedings of the 9th International Symposium on Jet Cutting Technology (Bedford, England) pp 495-511

Miranda R M and Kim T J 1996 Proceedings of the 13th International Symposium on Jet Cutting Technology (Bedford, England) pp 415-424 
Momber A W, Kovacevic R and Schuneman R 1993 Proceedings of the 7th American Water Jet Conference (Seattle, Washington, USA), pp 561-572

Nalbant M, Gökkaya H and Sur G 2007 Mater. \& Design 28 1379

Özçelik B, Öktem H and Kurtaran H 2005 Inter. J. Adv. Manufact. Technol. 27234
Şahin Y 2009 J. Mater. Process. Technol. 2093478

Valicek J, Drzik M, Hloch S, Ohlidal M, Miloslav L, Gombar M, Radvanska A, Hlavacek P and Palenikova K 2007 Int. J. Mach. Tools \& Manufact. 471786

Wang J and Wong W C K 1999 Inter. J. Machine Tools \& Manufac. 39855

Zeng J and Kim T J 1996 Wear 193207 